\section{Hormonal contraception and HIV/AIDS transmission: challenges for Zimbabwe's reproductive health service providers in promoting informed contraception choices}

\author{
Christopher Mafuva, ${ }^{1}$ \\ Hilda T. Marima-Matarira²
}

1'Department for Health, University of Bath, UK; ${ }^{2}$ Department of Chemical Pathology, University of Zimbabwe College of Health, Harare, Zimbabwe

\section{Abstract}

None-barrier methods are the most predominant contraceptive methods of choice among Zimbabwean women, with the contraceptive pill being the most popular. The spread of HIV/AIDS is most prevalent in sub-Saharan African countries, Zimbabwe included. The prevalent mode of transmission is unprotected heterosexual sex. Although Zimbabwe boasts of a high literacy rate some women may still be vulnerable like in other parts of the world, as they may not understand the role of the Zimbabwe National Family Planning Council (ZNFPC) and other reproductive health service providers. This is because some women at risk may expose themselves to unprotected sex while they are on hormonal contraceptives. This paper seeks to infer into pros and cons of hormonal contraceptive use among Zimbabwean women. There is also need to discuss the effectiveness of providers (ZNFPC clinics and the Ministry of Health) in educating women about the risk of HIV transmission, which may be associated with some non-barrier methods of contraception. An understanding of women's attitudes towards the different forms of contraception is of paramount importance as is that of the factors that could contribute to women in different social settings resorting to uninformed contraceptive choices.

\section{Introduction}

It has since been established that unprotected heterosexual sex is the predominant mode of HIV transmission among Zimbabweans. The Zimbabwe National Family Planning Council (ZNFPC) works in conjunction with the Ministry of Health clinics in distributing different types of contraceptives depending on the client's preferences. Previous research has noted that the contraceptive pill is the most popular method of family planning in Zimbabwe. $^{1,2}$ In Bolivia, Nicaragua and Zimbabwe, between $50 \%$ and $60 \%$ of sexually active unmarried women have used the pill whereas $80 \%$ of married women have used the pill in Brazil, as have two thirds of married Zimbabwean women. ${ }^{2}$ Use of the injectable depot is an alternative choice although it is not as popular among Zimbabwean women. ${ }^{2}$

While a number of studies found no significant association between hormonal contraception and HIV acquisition, a study of HIV-discordant couples in 7 African countries demonstrated a double risk of HIV transmission and acquisition associated with hormonal contraception. In this regard, it is argued that women at risk of HIV acquisition should be counseled about the potentially high risk of HIV acquisition with use of hormonal contraceptives. ${ }^{3}$ These findings relate well with another study carried out in Uganda, Zimbabwe and Thailand in which both combined oral contraceptive and depot-medroxyprogesterone (DPMA) users had an increased risk of HIV acquisition compared with non-hormonal group. ${ }^{4}$ These observations were statistically significant for DPMA while there was a weak correlation for combined oral contraceptives. Meanwhile research in South Africa does not rule out moderate increases in HIV risk transmission among DPMA users although there could be need to carry out further research., 5 The World Health Organization's technical statement on hormonal contraception and HIV maintains that because of the inconclusive nature of the causality and effect relationship, women can continue to use all existing hormonal contraceptives without restriction. It also encourages that women using hormonal contraceptives and at risk of HIV acquisition should be advised to always use condoms and other preventive measures. ${ }^{7}$ There is need to further explore the synergism between hormonal contraceptive use and unprotected sex among Zimbabwean women. Nanda et al. $^{8}$ undertook a study in Uganda, Zimbabwe and Thailand in which they found out that following HIV diagnosis, 135 (98.5\%) of 137 hormonal users continued hormonal contraceptives (HC) and 14 (25\%) of 57 nonusers began using HC. It is therefore important to infer into the behaviors of such HIV positive women on $\mathrm{HC}$ as this could pose a risk should they engage in indiscriminate and unprotected sex with multiple partners. Such an inference would also help to establish whether it maybe necessary for family planning clinics and other distributors of hormonal contraceptives to provide voluntary screening for HIV infection so that users receive counseling and are ultimately encouraged to use alternative forms of contraception such as barrier methods typified by the condom to avoid infection and re-infection with
Correspondence: Christopher Mafuva,

Spectroconnect Health Innovations

The Basement Goodmayes House,

45-49 Goodmayes Road, Ilford IG3 9UF, Essex, UK. Tel. +44.7411461056.

E-mail: C.Mafuva@bath.ac.uk;

chris@spectrohealth.co.uk

Key words: hormonal, contraception, HIV/AIDS Zimbabwe.

Acknowledgements: the authors would like to express their sincere gratitude to Dr Alan Buckingham from the Department for Health (University of Bath) for his invaluable guidance on approaches of appraising literature in line with research based practice and management in health services research.

Conflict of interests: the authors declare no potential conflict of interests.

Received for publication: 24 July 2013 .

Revision received: 11 October 2013.

Accepted for publication: 12 October 2013.

This work is licensed under a Creative Commons Attribution NonCommercial 3.0 License (CC BYNC 3.0).

(C) Copyright C. Mafuva and H.T. Marima-Matarira, 2013

Licensee PAGEPress, Italy

Journal of Public Health in Africa 2013; 4:e16 doi:10.4081/jphia.2013.e16

different strains of the virus. This helps to empower HIV positive women to make informed choices relating to their reproductive lives, free of cohesion. ${ }^{9}$

Media reports have highlighted that sex workers in Zimbabwe are yearning for alternative means of earning money, as they believe that such initiatives would go a long way in helping reduce the spread of HIV/AIDS. Some of these women have even raised concern that they believe most of their clients' wives will be infected despite their innocence as some men desist from using barrier methods such as condoms. ${ }^{10}$ There is thus need to embrace sex education as a tool to empower vulnerable women using HCs as they may be at risk of contracting HIV through unprotected sex.

Research by Kiddugavu et al.11 in Uganda found a weak association between use of hormonal contraceptives and HIV acquisition and this had no statistical significance following adjustment for behavioral confounding factors hence this cohort study allowed women to continue using their voluntarily chosen contraceptive. On the contrary, Mantel et al. ${ }^{12}$ and Nanda et al. ${ }^{8}$ clearly emphasize the need to use barrier methods such as the condoms in conjunction with HCs in order to reduce the risk of sexually contacting HIV and other sexually transmitted infections among women at risk. 
There is need to clarify this controversy so as to ensure that the nation is not at an epidemiologic risk of a more robust HIV/AIDS epidemic. This therefore justifies the need to evaluate the attitudes of women from different backgrounds, namely urban and rural settings to establish whether there are HIV risk transmission factors associated with use of HCs.

The World Health Organization and the Centers for Disease Control (CDC) emphasize that women at risk of HIV infection have access to and use either male or female condoms and if need be take other measures to prevent and reduce the risk of HIV and sexually transmitted infections. ${ }^{7,13}$ An update to CDC's United States medical eligibility criteria for contraceptive use acknowledges observational evidence suggesting direct evidence with regard to hormonal contraceptive use and female-to-male HIV transmission. It also acknowledges equivocal evidence with a number of studies finding a significant increase in risk for HIV acquisition among injectables whereas others did not. Newmann et al. ${ }^{14}$ maintain the need to design integrated family planning/HIV services in high HIV prevalence areas. In such areas, users may be focusing on the use of HCs as an effective method of preventing unwanted pregnancies while at the same time overlooking their vulnerability to HIV infection. It is therefore also important to infer as to whether providers of family planning services in Zimbabwe effectively educate contraceptive users about the importance of desisting from indiscriminate unprotected sex. The attitudes of HC users must also be elucidated in line with their perception of sexual behaviour with reference to HIV/AIDS spread.

\section{Implications for policy makers}

In this section, we advocate for an evidence based approach in which the policy makers need to infer into factors that motivate women to use different methods of contraception. This entails carrying both quantitative and qualitative inferences. We also envisage an inclusive approach in which relevant stakeholders such as the World Health Organization, United Nations agencies, Governmental and nonGovernmental organizations work in cohorts both during fundraising and capacity building.

\section{Research into contraceptive choices}

Evidence based practice entails research based outcomes that positively influence public health practice. To understand the predis- posing factors that may have contributed to the upsurge in use of hormonal contraceptives, there is need to carry out quantitative studies as the basis for epidemiological distributions. Due to tribal, religious and ethnic differences within Zimbabwe's heterogeneous population, it becomes paramount to infer into prevalence and incidence rates in these different communities. One may thus postulate the need for a positivist approach in which participants are counseled and tested for HIV/AIDS. There is need to correlate the incidence and prevalence rates to the different hormonal contraceptives used. Although the pill is the most prevalent form of hormonal contraceptive used, other forms such as the depot are in use. On the other hand, there are different choices of hormonal pills in use such as lofemenol, overate and other formulations. ${ }^{1}$ In this first approach, it is assumed that reality is objective and can only be experimentally deducted as depicted in empiricism. ${ }^{15}$ As Higgs and Herbert ${ }^{16}$ put it, such an experimental approach will facilitate objective deduction of the prevalence rate in our communities. The major limitation of such an approach is that extenuating factors that could have contributed to HIV acquisition and transmission are precluded as no personal experiences are expounded.

Having pointed the major limitation as lack of introspection in user's personal experiences, there is a need to compliment the clinical experimental research with a social construction model of research. Such a model is phenomenological hence dependent on people constructing their own experiences with regards to contraception and other compounding sexual experiences. ${ }^{17,18}$ This approach empowers researchers and policy makers to infer into service user's experiences of compounding HIV risk factors such as previous use of HCs, lack of knowledge or information, possible cohesion into unprotected sex life by their male partners, history of commercial sex life as well as different religious and/or ethnic backgrounds. In this regard, thematic coding may be used as an important tool to explore the mentioned variables.

\section{Need for stakeholder collaboration}

Having explored the factors that promote indiscriminate sex among $\mathrm{HC}$ users, there is need to educate the public about the risks and preventive measures for such experiences. In order to disseminate the issues of concern and educate the populace, there is need for resource mobilization. Zimbabwe being a low resource country, it is struggling to sustain the funding of most of its health programmes due to limited financial and human resources. The current political-economic dynamics have further marginalized Zimbabwe's economy. This necessitates the need for mobilizing resources as well as collaborative consultative workshops in which the ZNFPC, Ministry of Health and Child Welfare, other Governmental organizations and Non-Governmental organizations work in cohorts. There is also need to incorporate international bodies such as the United Nations, Global AIDS Fund and the World Health Organization. Reproductive health departments at local universities may be involved in designing curricula for the training programmes which may first be offered to middle managers from the Ministry of Health as well as the ZNFPC. These managers may in turn train the community-based educators. Training of community-based peer educators on different strategies to make the women conscious of $\mathrm{HC}$ use and the associated risks of HIV/AIDS must constitute the major objective during capacity building. The ZNFPC being the major provider of reproductive health services may initiate pilot peer education programmes. Once adopted by the policy makers and regulators, these awareness programmes may then be fully implemented cognizant of the observations noted during the community-based research.

\section{Conclusions}

The upsurge of HIV/AIDS is of concern in Sub-Saharan Africa, Zimbabwe included. With fewer women currently able to access comprehensive reproductive health education, there is need to promote hormonal contraceptive education in line with risks of HIV spread and acquisition. This entails collaborative efforts from different reproductive health stakeholders so as to enhance capacity building for health education providers.

\section{References}

1. Mafuva C, Djarova T, Matarira H. Influence of combined oral contraceptives on the onset of cervical intraepithelial neoplasia. Afr J Health Sci 2002;9:129-37.

2. Blackburn RD, Cunkelman A, Zildar VM. Oral contraceptives: an update. Pop Rep A 2000;(28):1-16.

3. Heffron R, Donnell D, Rees H, et al. Use of hormonal contraceptives and risk of HIV-1 transmission: a prospective cohort study. Lancet Infect Dis 2012;12:19-26.

4. Morrison C, Richardson B, Mmiro F, et al. Hormonal contraception and the risk of HIV acquisition. AIDS 2007;12:85-95. 
5. Kleinschmidt I, Rees H, Delany S, et al. Injectable progestin contraceptive use and risk of HIV infection in a South African family planning cohort. Contraception 2007;75:461-7.

6. Morrison CS, Skoler-Karpoff S, Kwok C, et al. Hormonal Contraception and the risk of HIV acquisition among women in South Africa. AIDS 2012;26:497-504.

7. WHO. Technical statement: hormonal contraceptive and HIV. WHO/RHR 12.08; pp 45. Available from: http://www.who.int/ reproductivehealth/topics/family_planning/Hormonal_contraception_and_HIV.p df Accessed: 4 June 2013.

8 8. Nanda K, Morrison CS, Kwok C, et al. Discontinuation of oral contraceptives and depot medroxyprogesterone acetate among women with and without HIV in Uganda, Zimbabwe and Thailand. Contraception 2011;83:542-8.
9. Delvaux T, Nostlinger C. Reproductive choice for women and men living with HIV: contraception, abortion and fertility. Reproductive Health Matters 2007;29 Suppl:46-66.

10. Chirara I. Sex workers yearn for clean money. The Standard, 14 May 2011. Available from: http://www.thestandard. co.zw/local/29657-sex-workers-yearn-forclean-money.html Accessed: 20 May 2011.

11. Kiddugavu M, Makumbi F, Wawer MJ, et al. Hormonal contraceptive use and HIV-1 infection in a population based cohort in Rakai, Uganda. AIDS 2003;17:233-40.

12. Mantel JE, Thomson C, Sambisa W, et al. International conference on AIDS. International AIDS Society. 1998;12:197 (abstract no. 13562). Available from: http://wwl.aegis.org/conferences/iac/1998/ 13562.html Accessed: January 2013.

13. Update to CDC's U.S. Medical eligibility criteria for contraceptive use, 2010: revised recommendations for the use of hormonal contraception among women at high risk for HIV infection or infected with HIV. MMWR 2012;61:449-52.

14. Newmann SJ, Mishra K, Onono M, et al. Providers' perspectives on provision of family planning to HIV-positive individuals in HIV care in Nyanza Province Kenya. Aids Res Treat 2013;2013:915-23.

15. Darlaston-Jones D. Making connections: the relationship between epistemology and research methods. Austr Commun Psychol 2007;19:19-27.

16. Higgs J, Herbert RD. Complementary research paradigms. Austr J Physiother 2004;(50):63-4.

17. Alderson $P$. The importance of theories in health care. Br Med J 2002;317:1007-10.

18. Stone P. Deciding upon and refining a question. Palliat Med 2002;16:265-7. 